\title{
Social Media Engagement and HIV Testing Among Men Who Have Sex With Men in China: A Nationwide Cross-Sectional Survey
}

Bolin $\mathrm{Cao}^{1,2}$, PhD; Chuncheng Liu ${ }^{2}, \mathrm{BA}$; Maya Durvasula ${ }^{3}$; Weiming Tang ${ }^{2,4}, \mathrm{PhD}$; Stephen $\mathrm{Pan}^{2}$, PhD; Adam J Saffer ${ }^{5}, \mathrm{PhD}$; Chongyi Wei ${ }^{6}$, PhD; Joseph D Tucker ${ }^{2,4}, \mathrm{MD}$

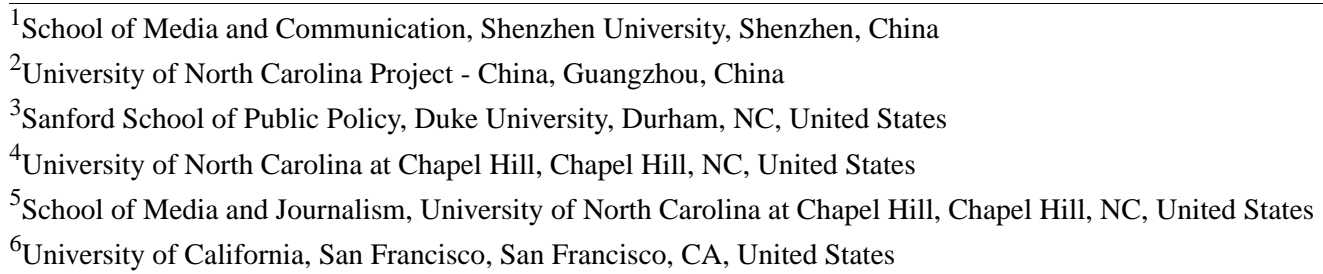

\section{Corresponding Author:}

Bolin $\mathrm{Cao}, \mathrm{PhD}$

School of Media and Communication

Shenzhen University

3688 Nanhai Road

Nanshan District

Shenzhen,

China

Phone: 8613247393943

Fax: 862087257353

Email: caobolin@szu.edu.cn

\section{Abstract}

Background: Many interventions find that social media engagement with health promotion materials can translate into behavioral changes. However, only a few studies have examined the ways in which specific actions on various social media platforms are correlated with health behaviors.

Objective: The objective of this study was to examine the association between social media use and HIV testing behaviors among Chinese men who have sex with men (MSM).

Methods: In July 2016, a Web-based survey was conducted to recruit MSM in 8 Chinese cities through Blued (Blue City Holdings Ltd.), the world's largest gay mobile phone app. Data on sociodemographic variables, social media use platforms and behaviors, sexual behaviors, and HIV testing histories were collected. HIV testing-related social media use was defined as having ever engaged with HIV testing content on social media, which was further divided into observing (ie, receiving), endorsing (eg, liking and sharing), and contributing (eg, posting or commenting on HIV testing materials). Confirmatory factor analysis (CFA) was conducted to determine the best division of HIV testing-related social media use. Univariate and multivariable logistic regressions were used to examine the association between HIV testing-related social media use and HIV testing behaviors.

Results: A total of 2105 individuals participated in the survey. Among them, $46.75 \%$ (984) were under the age of 24 years, $35.43 \%$ (746) had high school education or less, and 47.74\% (587) had condomless sex in the last 3 months. More than half of the respondents $(58.14 \%, 1224 / 2105)$ reported HIV testing-related social media use. Additionally, HIV testing-related social media use, especially on multifunctional platforms such as WeChat, was found to be associated with recent HIV testing (adjusted odds ratio [aOR] 2.32, 95\% CI 1.66-3.24). Contributing on social media was correlated with recent HIV testing (aOR 2.10, 95\% CI 1.40-3.16), but neither observing (aOR 0.66, 95\% CI 0.38-1.15) nor endorsing (aOR 1.29, 95\% CI 0.88-1.90) were correlated.

Conclusions: Our data suggest that social media use, particularly on multifunctional platforms such as WeChat and with contributing behaviors, is correlated with HIV testing among MSM in China. Campaigns that promote active participant contribution on social media beyond passive observation and endorsement of promotional materials are needed. This study has implications for the design and implementation of social media interventions to promote HIV testing. 
(J Med Internet Res 2017;19(7):e251) doi: 10.2196/jmir.7251

\section{KEYWORDS}

social Media; HIV; China; homosexuality; male; mobile application

\section{Introduction}

Social media components are increasingly being integrated into public health interventions. Web-based engagement with social media health promotion campaigns can translate into offline behavioral changes [1,2]. Mobile phone apps and related social media provide opportunities for men to locate potential sex partners in their vicinity; according to recent statistical data, men report opening such apps approximately 190 times per week [3]. Healthcare professionals are increasingly using social media to develop health promotion materials, distribute information, and establish peer-mentored education programs [4]. A wide range of social media interventions have been successfully implemented to improve health worldwide [5-7].

Although the effectiveness of social media interventions is well established, the relationship between social media engagement and relevant behavioral outcomes has not been fully explored $[8,9]$. In particular, detailed examination of the ways in which participants engage with social media platforms in public health interventions is scarce [10-12]. Functions and features vary between different social media platforms, with different platforms encouraging specific types of engagement (sharing, liking, commenting, etc). Identifying the effects of specific social media platforms and behaviors on health outcomes and taking advantage of them can help optimize health-related intervention effects [13].

For HIV prevention, low HIV testing rate is a major obstacle and a disruption to the continuum of care $[14,15]$. A large subgroup of men who have sex with men (MSM) and engage in high-risk sexual behaviors has never tested for HIV [16], thereby resulting in a sizable population of HIV-positive men who do not know their status [17,18]. Studies on MSM in the United States, the United Kingdom, and Thailand using social and sexual networking sites have demonstrated that social media interventions for HIV testing promotion are both feasible and effective [19-21]. Social media platforms, which are used by MSM across the world to expand social circles, help build community, find sexual partners [22,23], and allow public health practitioners to implement HIV testing promotion among MSM $[12,21,24]$.

In China, the rise in popularity of Web-based social and sexual networking sites has coincided with an increase in the prevalence of HIV infection among MSM in recent decades [25]. Social media platforms such as Weibo, WeChat, QQ, and gay apps are providing men with social and sexual networking opportunities and mediums for learning new information. In 2015, WeChat, a multifunctional social media platform based in China, reported 549 million monthly active users [26]. Meanwhile, between 2006 and 2014, the HIV infection rate among MSM rose from $2.5 \%$ to $25.8 \%$ [27]. As social media platforms are increasingly being integrated into Chinese daily life and public health interventions, there is a clear need for greater analysis of the specific effects of various forms of social media use on offline HIV testing behaviors [27,28]. This study uses data from a cross-sectional Web-based survey to examine the association between social media use by Chinese MSM and HIV testing behaviors.

\section{Methods}

\section{Recruitment}

We conducted a Web-based survey among MSM in 8 Chinese cities: Guangzhou, Shenzhen, Zhuhai, and Jiangmen (Guangdong Province, Southern China); and Jinan, Qingdao, Yantai, and Jining (Shandong Province, Northern China) in July 2016. This was a baseline survey of an intervention study to evaluate the promotion of HIV testing among MSM in China, and these 8 cities were chosen because they were urban cities with relatively high rates of HIV prevalence [27]. Protocol of the study was registered in the Clinical Trials.gov database (NCT02796963). We followed the Checklist for Reporting Results of Internet E-Surveys for reporting the development and findings of Web-based surveys [29]. The pretest survey was field tested by 30 MSM in April 2016, and their feedback was taken into account to finalize the survey questionnaire.

Participants were recruited through Blued, the world's largest gay mobile app [30]. Private short messages containing the survey link were sent to the registered Blued users in the 8 cities. The study used cellphone numbers to prevent multiple entries from the same individual. Duplicated responses were excluded from the analysis. The eligible participants included those who were born biologically male, had ever engaged in anal sex with a man, were at least 16 years of age, were currently living in one of the designated 8 cities, were willing to provide their cell phone number, and were willing to complete an informed consent procedure. All eligible participants signed an electronic informed consent form before completing the survey and received a small phone card reimbursement or WeChat Red Envelope (hongbao), equivalent to roughly US \$7.5.

\section{Measures}

Sociodemographic information collected in the survey (full survey attached as Multimedia Appendix 1) included age, education, income, and marital status. Questions on sexual orientation and disclosure of sexual orientation to others were also included. Participants were asked about their sexual histories and behaviors, including the number of sex partners and condom use practices in the past 3 months. The survey also included questions on HIV testing behaviors, including past HIV testing (beforethe recent 3 months) and testing for HIV in the preceding 3 months. We focused on HIV testing in the past 3 months as outcome to reduce recall bias and to remain consistent with questions about social media use within the past 3 months. These measures had been used in previous Web-based surveys among MSM in China [31]. 
The survey included a section on social media use, in which participants were asked whether they had ever engaged with any content related to HIV testing on social media in the past and, specifically, whether they had done so in the past 3 months. In this study, we defined HIV testing-related social media use as having ever engaged on a social media platform with any information or materials that mention or promote HIV testing.

Men who reported HIV testing-related social media use were further asked about specific behaviors on 4 social and sexual networking platforms: Weibo, QQ, WeChat, and gay-specific dating apps. Weibo is a Chinese microblogging platform, similar to Twitter, where users can publicly broadcast short messages (under 140 Chinese characters) to their friends and followers [32]. Both QQ and WeChat are Chinese instant messaging platforms that provide multiple functions, including communication, information, entertainment, and financial services [33]. Whereas QQ is optimized for desktop use [34], WeChat is optimized for mobile phone use [26]. Gay-specific dating and networking apps mainly refer to Blued, a Chinese app with 27 million registered users. Other gay apps included Hornet, Grindr, and Zank, which are all available on mobile phones and allow participants to meet new sexual partners [35].

In addition, men who reported HIV testing-related social media use in the past 3 months were asked whether they had ever received, liked, or commented on information related to HIV testing or whether they had ever shared materials on their own timelines, forwarded them to others, or discussed them in one-on-one or group messages on various social and sexual networking platforms. These categories of social media activities were adopted and revised from previous studies, which distinguish behaviors based on the differing levels of time investment and effort required [36,37]. In particular, specific social media use behaviors in the past 3 months were categorized into three groups: observing, which included receiving HIV testing information; endorsing, which included liking HIV testing materials, forwarding them to others, and sharing them on timelines; and contributing, which included posting original information, commenting on someone else's post about HIV testing, and participating in one-on-one or group chats [38,39].

\section{Statistical Analysis}

Descriptive statistics were used to describe men's sociodemographic information, sexual risk behaviors, and social media use. Bivariate analysis was used to examine factors associated with HIV testing-related social media use.

Confirmatory factor analysis (CFA) was conducted to confirm the division of social media use into more specific categories. The indicators of CFA included the chi-squared test of minimum discrepancy divided by degrees of freedom (CMIN/DF), goodness of fit index (GFI), adjusted goodness of fit index (AGFI), normed fit index (NFI), comparative fit index (CFI), and root mean square error of approximation (RMSEA). The CMIN/DF assesses the fit of a model in CFA and modeling in which the minimum discrepancies are divided by its degrees of freedom. The value of CMIN/DF should ideally be less than 2.0. The GFI is a measure of fit between the hypothesized model and the observed covariance matrix; the AGFI corrects GFI, which is affected by the number of indicators of each latent variable. The GFI and AGFI range between 0 and 1, with a value of over .9 generally indicating an acceptable model fit. The NFI analyzes the discrepancy between the chi-squared value of the hypothesized model and the chi-squared value of the null model. Values for the NFI should range between 0 and 1, with a cutoff of .95 or greater indicating a good model fit. The CFI analyzes the model fit by examining the discrepancy between the data and the hypothesized model while adjusting for the issues of sample size. The CFI values range from 0 to 1 , with larger values indicating a better fit. A CFI value of .95 or higher is presently accepted as an indicator of good fit. The RMSEA examines the discrepancy between the hypothesized model with optimally chosen parameter estimates and the population covariance matrix. The RMSEA ranges from 0 to 1 , with smaller values indicating a better model fit. A value of .06 or less is indicative of an acceptable model fit.

Logistic regressions (univariate and multivariable) were used to examine the relationship between HIV testing-related social media use and HIV testing behaviors. Multivariable logistic regression models were adjusted for potential confounding variables, including age, education, income, marital status, sexual orientation, disclosure of sexual orientation to others, partner status (primary partner, multiple partners, etc) and past HIV testing (before the recent 3 months). As social media platforms are designed for and encourage different actions and behaviors, this study controlled for platforms while examining the effect of specific Web-based actions on offline behavior $[40,41]$.

\section{Ethical Statement}

This study was approved by the ethics review committees at the Guangdong Provincial Center for Skin Diseases and STI Control; the University of North Carolina, Chapel Hill (14-1685); and the University of California, San Francisco (14-14877) before the survey launch.

\section{Results}

\section{Study Participants}

The survey link distributed on Blued was clicked 36,863 times in 3 days, with 25,141 unique Internet Protocol addresses automatically collected by the survey tool. Of these clicks, 2112 individuals met the study eligibility criteria and completed the questionnaire in its entirety. Seven responses were deleted as duplicates. Overall, 2105 eligible men from the 8 designated cities were included in the final analysis. The percentages of participants who were from Guangzhou, Shenzhen, Zhuhai, Jiangmen, Jinan, Qingtao, Yantai, and Jining were $14.68 \%$ (309), $14.87 \%$ (313), 11.21\% (236), 9.07\% (191), $13.21 \%$ (278), $13.92 \%$ (293), $12.92 \%$ (272), and $10.12 \%$ (213), respectively.

\section{Demographics and Behaviors}

Of the 2105 men who participated in the survey, $46.75 \%$ (984) were under the age of 24 years, and $35.44 \%$ (746) had high school education or less. Most men $(85.94 \%, 1809)$ were never married, and $61.24 \%$ of men (1289) had an annual income over US \$5500. 
Table 1. Sociodemographic and behavioral characteristics of men who have sex with men in 8 Chinese cities, 2016 (N=2105).

\begin{tabular}{|c|c|}
\hline Characteristics & Total, n (\%) \\
\hline \multicolumn{2}{|l|}{ Age (years) } \\
\hline$\leq 24$ & $984(46.75 \%)$ \\
\hline$>24$ & $1121(53.25 \%)$ \\
\hline \multicolumn{2}{|l|}{ Education } \\
\hline High school or below & $746(35.44 \%)$ \\
\hline Some college & $583(27.70 \%)$ \\
\hline College or above & $776(36.86 \%)$ \\
\hline \multicolumn{2}{|l|}{ Annual income (US \$) } \\
\hline$<2700$ & $391(18.57 \%)$ \\
\hline $2700-5500$ & $425(20.19 \%)$ \\
\hline $5501-9200$ & $690(32.78 \%)$ \\
\hline $9201-15,000$ & $384(18.24 \%)$ \\
\hline$>15,000$ & $215(10.21 \%)$ \\
\hline \multicolumn{2}{|l|}{ Marital status } \\
\hline Never married & $1809(85.94 \%)$ \\
\hline Ever married & $296(14.06 \%)$ \\
\hline \multicolumn{2}{|l|}{ Sexual orientation } \\
\hline Gay & $1524(72.40 \%)$ \\
\hline Bisexual & $496(23.56 \%)$ \\
\hline Heterosexual & $11(0.53 \%)$ \\
\hline Unsure & $74(3.52 \%)$ \\
\hline \multicolumn{2}{|c|}{ Ever disclosed sexuality to others } \\
\hline Yes & $1426(67.74 \%)$ \\
\hline No & $679(32.26 \%)$ \\
\hline \multicolumn{2}{|c|}{ Main partner in the past 3 months } \\
\hline Yes & $812(38.57 \%)$ \\
\hline No & $1293(61.43 \%)$ \\
\hline \multicolumn{2}{|c|}{ Number of sexual partners in the past 3 months } \\
\hline $0-1$ & $1477(70.17 \%)$ \\
\hline Multiple & $628(29.83 \%)$ \\
\hline \multicolumn{2}{|c|}{ Consistent condom use in the past 3 months ${ }^{a}$} \\
\hline Yes & $643(52.28 \%)$ \\
\hline No & $587(47.72 \%)$ \\
\hline \multicolumn{2}{|c|}{ Past HIV testing before the recent 3 months } \\
\hline Yes & $628(29.83 \%)$ \\
\hline No & $1477(70.17 \%)$ \\
\hline \multicolumn{2}{|c|}{ Tested for HIV in the past 3 months } \\
\hline Yes & $687(32.64 \%)$ \\
\hline No & $1418(67.36 \%)$ \\
\hline \multicolumn{2}{|c|}{ Ever HIV testing-related social media use } \\
\hline Yes & $1224(58.15 \%)$ \\
\hline No & $881(41.85 \%)$ \\
\hline
\end{tabular}




\begin{tabular}{ll}
\hline Characteristics & Total, $\mathrm{n}(\%)$ \\
\hline HIV testing-related social media use in the past 3 months & \\
Yes & $954(45.32 \%)$ \\
No & $1151(54.68 \%)$ \\
\hline
\end{tabular}

${ }^{\mathrm{a}}$ Men who reported having sex within the past 3 months were asked about consistent condom use ( $\left.\mathrm{N}=1230\right)$.

Nearly three-fourths $(72.40 \%, 1524)$ of men self-identified as gay, and over two-thirds $(67.74 \%, 1426)$ had ever disclosed their sexual orientation to others. Over one-third $(38.57 \%, 812)$ reported a main sexual partner in the past 3 months. Nearly one-third $(29.83 \%, 628)$ had multiple sexual partners, and $47.72 \%$ (587) did not consistently use condoms among the men who had sex in the last 3 months. Nearly one-third $(29.83 \%$, 628 ) of respondents had tested for HIV before the recent 3 months, and $32.64 \%$ (687) had been tested in the past 3 months. Among respondents, 58.15\% (1224) reported ever HIV testing-related social media use, and $45.32 \%$ (954) reported such experience in the last 3 months (Table 1).

\section{Specific HIV Testing-Related Social Media Use Categories}

CFA indicated that the model of specific social media use categories had a good fit (CMIN/DF=2.56, GFI=.99, AGFI=.98, $\mathrm{NFI}=.99, \mathrm{CFI}=.99, \mathrm{RMSEA}=.04)$. Of the three social media use categories, observing occurred most frequently on gay mobile apps $(460,48.2 \%)$, followed by WeChat $(396,41.5 \%)$. Endorsing occurred most frequently on WeChat: $26.8 \%$ (256) had liked HIV testing-related information, 17.2\% (164) had forwarded such information to others, and $18.6 \%$ (177) had shared HIV-related materials on their own timelines. Contributing was a common behavior on both WeChat and QQ. Men posted original information about HIV testing on WeChat
$(154,16.1 \%)$ and QQ $(146,15.3 \%)$; commented on others' posts on WeChat $(186,19.5 \%)$ and QQ $(150,15.7 \%)$; had one-on-one chats about HIV testing on WeChat $(265,27.8 \%)$ and QQ (237, $24.8 \%)$; and had group chats on WeChat $(226,23.7 \%)$ and QQ $(247,25.9 \%)$. Men tended to be least likely to use Weibo to conduct HIV testing-related behaviors (Table 2).

\section{Correlates of HIV Testing-Related Social Media Use}

In bivariate analyses, age, education, income, and marital status were not correlated with HIV testing-related social media use. Self-identified gay men reported HIV testing-related social media use in the past 3 months more frequently than heterosexual and bisexual men $\left(74.5 \%\right.$ vs $70.63 \%, \chi_{1}^{2}=3.9$, $P=.047)$. Men who had ever disclosed sexual orientation to others were more likely to report HIV testing-related social media use $\left(73.2 \%\right.$ vs $\left.63.25 \%, \chi_{1}^{2}=23.5, P<.001\right)$. Men who had main partners in the past 3 months were more likely to report HIV testing-related social media use $(41.8 \%$ vs $35.88 \%$, $\left.\chi_{1}^{2}=7.8, P=.01\right)$.

Compared with men without HIV testing-related social media use, men with HIV testing-related social media use were more likely to have had multiple sexual partners in the past 3 months (33.2\% vs $\left.27.02 \%, \chi_{1}{ }_{1}=9.6, P=.01\right)$, and have been recently tested for HIV ( $40.5 \%$ vs $\left.26.15 \%, \chi_{1}^{2}=48.6, P<.001\right)$ (Table 3$)$.

Table 2. Specific social media use platforms and behaviors in the past 3 months among men who have sex with men in 8 Chinese cities, 2016 (N=954). Weibo is a Chinese microblogging platform, akin to Twitter; QQ and WeChat are Chinese instant messaging platforms, with QQ largely optimized for desktop computers and WeChat optimized for mobile phones; gay apps refer to gay-specific networking apps.

\begin{tabular}{|c|c|c|c|c|}
\hline Behaviors & Weibo, n (\%) & WeChat, n (\%) & QQ, n (\%) & Gay apps, $\mathrm{n}(\%)$ \\
\hline \multicolumn{5}{|l|}{ Observing } \\
\hline Received information about HIV testing & $227(23.8 \%)$ & $396(41.5 \%)$ & $318(33.3 \%)$ & $460(48.2 \%)$ \\
\hline \multicolumn{5}{|l|}{ Endorsing } \\
\hline Liked information about HIV testing & $180(18.9 \%)$ & $256(26.8 \%)$ & $189(19.8 \%)$ & $240(25.2 \%)$ \\
\hline Forwarded information about HIV testing to others & $120(12.6 \%)$ & $164(17.2 \%)$ & $139(14.6 \%)$ & $141(14.8 \%)$ \\
\hline Shared information on timeline about HIV testing & $108(11.3 \%)$ & $177(18.6 \%)$ & $134(14.0 \%)$ & $146(15.3 \%)$ \\
\hline \multicolumn{5}{|l|}{ Contributing } \\
\hline Posted original information about HIV testing & $90(9.4 \%)$ & $154(16.1 \%)$ & $146(15.3 \%)$ & $138(14.5 \%)$ \\
\hline Commented on others' post about HIV testing & $103(10.8 \%)$ & $186(19.5 \%)$ & $150(15.7 \%)$ & $179(18.8 \%)$ \\
\hline One-on-one chatted about HIV testing & $101(10.6 \%)$ & $265(27.8 \%)$ & $237(24.8 \%)$ & $206(21.6 \%)$ \\
\hline Group chatted about HIV testing & $85(8.9 \%)$ & $226(23.7 \%)$ & $247(25.9 \%)$ & $175(18.3 \%)$ \\
\hline
\end{tabular}


Table 3. Comparison of sociodemographic and behavioral characteristics between men with HIV testing-related social media use and men without among men who have sex with men in 8 Chinese cities, 2016 ( $\mathrm{N}=2105)$.

Sociodemographic and behavioral characteristics

\section{Age, in years}

$\leq 24$
$>24$

\section{Education}

High school or below

Some college

College or above

\section{Annual income (US \$)}

$<2700$

\section{0-5500}

5501-9200

9201-15,000

$>15,000$

\section{Marital status}

$$
\text { Never married }
$$

Ever married

\section{Sexual orientation}

Gay

Others $^{\mathrm{a}}$

Ever disclosed sexuality to others

Yes

No

Multiple

Consistent condom use in the past 3 months

Yes

No

Past HIV testing before the recent 3 months

Yes

No

Tested for HIV in the past 3 months

Yes

No
698 (73.2)

$256(26.8)$

399 (41.8)

555 (58.2)

637(66.8)

317 (33.2)

Men with HIV testing-

$(\mathrm{N}=954), \mathrm{n}(\%)$

305 (32.0)

$278(29.1)$

371 (38.9)

$165(17.3)$

195 (20.4)

$313(32.8)$

169 (17.7)

112 (11.7)

813 (85.2)

$711(74.5)$

$243(25.5)$

813 (70.63)

338 (29.37)

728 (63.25)

423 (36.75)

413 (35.88)

738 (64.12)

840 (72.98)

311 (27.02)

$329(55.0)$

$269(45.0)$

314 (49.68)

318 (50.32)

277 (29.0)

677 (71.0)

$386(40.5)$

$568(59.5)$

$600(52.13)$

405 (35.19)

226 (19.64)

377 (32.75)

215 (18.68)

$103(8.95)$

$996(86.53)$

155 (13.47)

800 (69.50)

301 (26.15)
1.3

9.2

.01

5.8

.21

0.8 .047

4.0

48.6 $<.001$

${ }^{\mathrm{a} O t h e r s ~ r e f e r s ~ t o ~ h e t e r o s e x u a l ~ a n d ~ b i s e x u a l . ~}$ 
Table 4. Correlations between HIV testing-related social media use and HIV-related behaviors among men who have sex with men in 8 Chinese cities, $2016(\mathrm{~N}=2105)$.

\begin{tabular}{ll}
\hline HIV-related behaviors & $\begin{array}{l}\text { Recent HIV testing-related social media use } \\
\text { Adjusted odds ratio (95\% CI) }\end{array}$ \\
\hline $\begin{array}{l}\text { Number of sexual partner(s) in the past 3 months } \\
0-1\end{array}$ & Ref \\
Multiple & $1.23^{\mathrm{a}}(1.01-1.50)$ \\
Consistent condom use in the past 3 months & $1.28^{\mathrm{a}}(1.01-1.61)$ \\
Yes & Ref \\
No & \\
Tested for HIV in the past 3 months & $2.02^{\mathrm{b}}(1.63-2.52)$ \\
Yes & Ref \\
No &
\end{tabular}

${ }^{\mathrm{a}} P<.05$.

${ }^{\mathrm{b}} P<.001$.

\section{Multivariable Analyses of Social Media Use and HIV Testing}

Multivariable logistic analysis showed that HIV testing-related social media use was significantly associated with the number of sexual partners (adjusted odds ratio [aOR]1.23, 95\% CI1.01-1.50) and consistent condom use behaviors (aOR1.27, 95\% CI1.01-1.60) in the past 3 months after adjusting for potential confounders. Furthermore, HIV testing-related social media use was also significantly associated with recent HIV testing (aOR2.02, 95\% CI 1.63-2.52; Table 4).

Multivariable analysis controlled for age, education, income, marital status, sexual orientation, disclosure status, main partner in the past 3 months, and past HIV testing before the recent 3 months.
There was a platform-linked variation in the relationship between HIV testing-related social media use and HIV testing behaviors in the past 3 months (Table 5). WeChat use was significantly associated with recent HIV testing (aOR2.32, 95\% CI 1.66-3.24), but Weibo (aOR 0.88, 95\% CI 0.62-1.25), QQ (aOR1.34, 95\% CI 0.96-1.86), and gay app (aOR0.80, 95\% CI $0.57-1.11$ ) use were not. Table 5 also indicated the relationship between specific HIV testing-related social media use and recent HIV testing behaviors. Contributing on social media was significantly associated with recent HIV testing (aOR2.10, 95\% CI 1.40-3.16). Endorsing on social media was significantly correlated with recent HIV testing in bivariate analysis (Crude OR1.46, 95\% CI 1.11-1.92) but not in multivariable analysis (aOR1.29, 95\% CI0.88-1.90).

Multivariable analysis controlled for age, education, income, marital status, sexual orientation, disclosure status, main partner in the past 3 months, and past HIV testing. 
Table 5. Correlations between specific social media use platforms and HIV testing behaviors in the past 3 months among men who have sex with men in 8 Chinese cities, $2016(\mathrm{~N}=954)$.

\begin{tabular}{|c|c|c|c|}
\hline \multirow[t]{2}{*}{ Characteristic } & \multicolumn{3}{|c|}{ Recent HIV testing } \\
\hline & $\mathrm{n}(\%)$ & $\begin{array}{l}\text { Crude odds ratio } \\
(95 \% \mathrm{CI})\end{array}$ & $\begin{array}{l}\text { Adjusted odds ratio } \\
(95 \% \mathrm{CI})\end{array}$ \\
\hline \multicolumn{4}{|c|}{ Social media use platforms } \\
\hline \multicolumn{4}{|l|}{ Weibo use } \\
\hline Yes & $307(32.2 \%)$ & $0.98(0.74-1.29)$ & $0.88(0.62-1.25)$ \\
\hline No & $647(67.8 \%)$ & & \\
\hline \multicolumn{4}{|c|}{ WeChat use } \\
\hline Yes & $561(58.8 \%)$ & $1.94^{\mathrm{a}}(1.48-2.54)$ & $2.32^{\mathrm{a}}(1.66-3.24)$ \\
\hline No & $393(41.2 \%)$ & & \\
\hline \multicolumn{4}{|l|}{ QQ use } \\
\hline Yes & $464(48.6 \%)$ & $1.33^{\mathrm{b}}(1.03-1.72)$ & $1.34(0.96-1.86)$ \\
\hline No & $490(51.4 \%)$ & & \\
\hline \multicolumn{4}{|c|}{ Gay app use } \\
\hline Yes & $561(58.8 \%)$ & $0.87(0.67-1.13)$ & $0.80(0.57-1.11)$ \\
\hline No & $393(41.2 \%)$ & & \\
\hline \multicolumn{4}{|c|}{ Social media use behaviors } \\
\hline \multicolumn{4}{|c|}{ Observing $^{c}$} \\
\hline Yes & $842(88.3 \%)$ & $1.37(0.91-2.08)$ & $0.66(0.38-1.15)$ \\
\hline No & $112(11.7 \%)$ & & \\
\hline \multicolumn{4}{|c|}{ Endorsing ${ }^{c}$} \\
\hline Yes & $614(64.4 \%)$ & $1.46^{\mathrm{d}}(1.11-1.92)$ & $1.29(0.88-1.90)$ \\
\hline No & $340(35.6 \%)$ & & \\
\hline \multicolumn{4}{|c|}{ Contributing ${ }^{c}$} \\
\hline Yes & $664(69.6 \%)$ & $2.09^{\mathrm{a}}(1.56-2.82)$ & $2.10^{\mathrm{a}}(1.40-3.16)$ \\
\hline No & $290(30.4 \%)$ & & \\
\hline
\end{tabular}

${ }^{\mathrm{a}} P<.001$.

${ }^{\mathrm{b}} P<.05$.

${ }^{\mathrm{c}}$ Multivariable analysis controlled social media platforms that included Weibo, WeChat, QQ, and gay apps. ${ }^{\mathrm{d}} P<.01$.

\section{Discussion}

\section{Principal Findings}

The rise of social media has created a set of promising tools for HIV prevention [2,12,21]. This study examines the relationship between specific social media engagement and HIV testing behavior, providing information necessary to optimize public health efforts on social media. In particular, this study expands the literature by examining associations between social media use and HIV testing, dividing social media use into specific platforms and behaviors, and examining MSM in a middle-income country. Although several previous studies have treated social media as a generic platform [6,42], this study acknowledges the important versatility of social media platforms and specifically focuses on the ways in which social media use is related to HIV testing.

We found that over half of MSM reported HIV testing-related social media use. This is consistent with past studies that have found that MSM commonly use social media to obtain information about HIV testing [23,42-44]. Additionally, ongoing public health interventions use social media to provide information about HIV testing sites, counseling, and self-testing kits $[7,45,46]$. As health interventions increasingly seek to integrate technology into healthcare services, there would be more chances for MSM to get engaged with HIV testing on social media [47].

HIV testing-related social media use was positively associated with recent HIV testing. This finding supports the positive 
association between Web-based engagement with offline health behaviors [48-50]. It is consistent with the literature from other fields (eg, smoking cessation) showing that social media use is related to offline behaviors [51-53]. Social media has several key advantages, which encourage this link between Web-based engagement and offline behavior. In particular, social media platforms allow public health campaigns to reach more diverse audiences, reduce overall cost, provide opportunities for repeated exposure to messaging, collect real-time feedback, and encourage direct engagement with messaging materials [13]. Men who engage in HIV testing-related social media use may receive detailed information about the testing location, hours of operation, and available services, thus potentially encouraging HIV testing [54].

Certain social media platforms and behaviors are strongly linked to recent HIV testing. WeChat use, in particular, was strongly correlated with recent HIV testing in this study. This is consistent with research showing that instant messaging platforms promote HIV testing in China [55] and the United States [56]. In addition, WeChat's popularity in China and its functional design are particularly conducive to the modes of engagement necessary for impactful public health interventions. On average, an adult in China spends more than 40 min per day on WeChat, and more than half of all users open WeChat more than 10 times per day [57]. The high-frequency use and constant engagement creates many opportunities for target audiences to be exposed to the messaging. Additionally, WeChat's design, which is optimized for mobile phone use and includes services for information, entertainment, and finance within a single app, encourages users to merge their online and offline activities $[26,58]$. Some community-based organizations have taken advantage of WeChat's interactive functions and now allow HIV test appointment scheduling through the app [59]. An ongoing randomized controlled trial is examining the effectiveness of using WeChat to promote HIV testing [60].

Contributing on social media was strongly correlated with recent HIV testing as compared with observing and endorsing. Among the three specific behaviors, observing represents a type of passive involvement that allows men to encounter information without directly engaging [61]. Although receiving information about HIV testing on social media is commonly reported, previous studies have not found this to be associated with HIV testing [62]. Endorsing represents greater engagement, as individuals must consciously present a position of approval or support to certain persons, information, or actions. However, endorsing can include what is often referred to as "slacktivism," a term indicating actions that are performed online to demonstrate public concern for an issue without requiring significant time or involvement [63]. These public displays of pseudo-engagement may not be conducive to behavioral change, and in fact, may represent detachment from actual behavior by making participants believe that they have already made some significant effort [64]. Compared with observing and endorsing, contributing on social media requires a higher level of cognitive engagement, as individuals need to develop some original perspectives or responses to the issue [65]. Contributing on social media may lead to positive health-related outcomes and influence behavior change [50]. When contributing on social media, men must think through the challenge and cognitively respond to the situation. This contribution process focuses participants' attention and increases overall comprehension of HIV testing issues, encouraging the translation of Web-based activity to actual behavior [66]. This finding is consistent with the theory that social, participatory, and interactive aspects of social media can promote healthy behavior change $[11,67]$.

This study is particularly relevant for policymakers and researchers who seek to use social media to promote behavior change. Although additional randomized controlled studies are needed to further examine the relationship between social media engagement and offline behavior, this study supports the integration of multifunctional platforms, such as WeChat, into public health interventions. Additionally, researchers and policymakers should encourage authentic input from MSM when designing social media interventions. The active engagement of MSM on social media is preferable to top-down, one-sided health communication [68]. Interactive activities, such as community crowdsourcing contests [69] that encourage higher levels of participation, can be organized in part through social media [70].

\section{Limitations}

This study also has limitations. First, men were recruited from a gay-specific social media platform, likely resulting in overestimation of the rate of social media use. Second, it is a cross-sectional survey, so causal relationships were not established. Response rates and completion rate were not calculated for this Web-based survey. Third, only 8 cities in China were selected; although cities of various sizes were included, the results are not necessarily applicable for rural areas. Given the variation in HIV infection and HIV testing rates between urban and rural areas of China [71], as well as the varying usage of social media as sources of health information [72], future studies are needed to test the feasibility of social media intervention in rural places. Finally, whereas social media platforms share similar characteristics, the landscape of social media tools and functions varies across nations. Further evaluation is needed to understand the feasibility and effectiveness of specific social media use in international contexts.

\section{Conclusions}

Social media interventions have been increasingly incorporated into public health programs $[4,12]$. This study suggests that Web-based engagement with HIV testing content may spur offline HIV testing behaviors, supporting the role of social media in public health campaigns. Our research suggests that future social media interventions can consider moving beyond merely using social media as a way to disseminate information and should instead leverage the interactive capabilities of various platforms to encourage participation. 


\section{Acknowledgments}

This work was supported by the National Institutes of Health (National Institute of Allergy and Infectious Diseases 1R01AI114310); UNC-South China STD Research Training Centre (Fogarty International Centre 1D43TW009532); UNC Center for AIDS Research (National Institute of Allergy and Infectious Diseases 5P30AI050410)]; University of California San Francisco Center for AIDS Research (National Institute of Allergy and Infectious Diseases P30 AI027763); and the Bill \& Melinda Gates Foundation to the MeSH Consortium (BMGF-OPP1120138). This publication was also supported by Grant Number UL1TR001111 from the National Center for Advancing Translational Sciences (NCATS) at the National Institutes of Health. We thank Dr Lisa B Hightow-Weidman, Dr Kathryn E Muessig, Dr Hongyun Fu, Dr Jason Ong, and anonymous reviewers for helpful comments. We also thank all the team members of the UNC project — China, and the participants who contributed to this study.

\section{Conflicts of Interest}

None declared.

\section{Multimedia Appendix 1}

Full survey questionnaire.

[PDF File (Adobe PDF File), 137KB-Multimedia Appendix 1]

\section{References}

1. Ramallo J, Kidder T, Albritton T, Blick G, Pachankis J, Grandelski V, et al. Exploring social networking technologies as tools for HIV prevention for men who have sex with men. AIDS Educ Prev 2015 Aug;27(4):298-311. [doi:

10.1521/aeap.2015.27.4.298] [Medline: 26241381]

2. Young SD, Szekeres G, Coates T. The relationship between online social networking and sexual risk behaviors among men who have sex with men (MSM). PLoS One 2013 May 01;8(5):e62271. [doi: 10.1371/journal.pone.0062271] [Medline: 23658716]

3. Cheetah Lab. 2017. China App rankings in the first quarter of 2017 URL: http://lab.cmcm.com/sjfx/2017-04-14/170.html [accessed 2017-04-24] [WebCite Cache ID 6pxbo0rZk]

4. Tso LS, Tang W, Li H, Yan HY, Tucker JD. Social media interventions to prevent HIV: a review of interventions and methodological considerations. Curr Opin Psychol 2016 Jun 01;9:6-10 [FREE Full text] [doi: 10.1016/j.copsyc.2015.09.019] [Medline: 26516632]

5. Chang T, Chopra V, Zhang C, Woolford SJ. The role of social media in online weight management: systematic review. J Med Internet Res 2013 Nov 28;15(11):e262 [FREE Full text] [doi: 10.2196/jmir.2852] [Medline: 24287455]

6. Duke JC, Hansen H, Kim AE, Curry L, Allen J. The use of social media by state tobacco control programs to promote smoking cessation: a cross-sectional study. J Med Internet Res 2014 Jul 10;16(7):e169 [FREE Full text] [doi: 10.2196/jmir.3430] [Medline: 25014311]

7. Young SD, Holloway I, Jaganath D, Rice E, Westmoreland D, Coates T. Project HOPE: online social network changes in an HIV prevention randomized controlled trial for African American and Latino men who have sex with men. Am J Public Health 2014 Sep;104(9):1707-1712. [doi: 10.2105/AJPH.2014.301992] [Medline: 25033137]

8. American Institute for Research. 2016. Health behavior change in a digital environment URL: http://www.air.org/topic/ health-and-wellness-across-lifespan/health-behavior-change-digital-environment [accessed 2017-01-03] [WebCite Cache ID 6nEGqxBT1]

9. Paek H, Hove T, Jung Y, Cole RT. Engagement across three social media platforms: an exploratory study of a cause-related PR campaign. Public Relat Rev 2013 Dec;39(5):526-533. [doi: 10.1016/j.pubrev.2013.09.013]

10. Carrotte ER, Vella AM, Lim MS. Predictors of "Liking" three types of health and fitness-related content on social media: a cross-sectional study. J Med Internet Res 2015 Aug 21;17(8):e205 [FREE Full text] [doi: 10.2196/jmir.4803] [Medline: 26297689]

11. Chou WY, Hunt YM, Beckjord EB, Moser RP, Hesse BW. Social media use in the United States: implications for health communication. J Med Internet Res 2009 Nov 27;11(4):e48 [FREE Full text] [doi: 10.2196/jmir.1249] [Medline: 19945947]

12. Tucker JD, Cao B, Li H, Tang S, Tang W, Wong NS, et al. Social media interventions to promote HIV testing. Clin Infect Dis 2016 Jul 15;63(2):282-283. [doi: 10.1093/cid/ciw297] [Medline: 27161778]

13. Heldman AB, Schindelar J, Weaver JB. Social media engagement and public health communication: implications for public health organizations being truly "Social”. Public Health Rev 2013 Jun 3;35:13. [doi: 10.1007/bf03391698]

14. Choi KH, Lui H, Guo Y, Han L, Mandel JS. Lack of HIV testing and awareness of HIV infection among men who have sex with men, Beijing, China. AIDS Educ Prev 2006 Feb;18(1):33-43. [doi: 10.1521/aeap.2006.18.1.33] [Medline: 16539574]

15. Fernández-Balbuena S, Hoyos J, Rosales-Statkus ME, Nardone A, Vallejo F, Ruiz M, Madrid HIV rapid testing group, et al. Low HIV testing uptake following diagnosis of a sexually transmitted infection in Spain: implications for the implementation of efficient strategies to reduce the undiagnosed HIV epidemic. AIDS Care 2016;28(6):677-683. [doi: 10.1080/09540121.2015.1123808] [Medline: 26837210] 
16. Adam PC, de Wit JB, Toskin I, Mathers BM, Nashkhoev M, Zablotska I, et al. Estimating levels of HIV testing, HIV prevention coverage, HIV knowledge, and condom use among men who have sex with men (MSM) in low-income and middle-income countries. J Acquir Immune Defic Syndr 2009 Dec;52(Suppl 2):S143-S151. [doi: 10.1097/QAI.0b013e3181baf111] [Medline: 19901627]

17. Centers for Disease Control and Prevention (CDC). HIV testing among men who have sex with men--21 cities, United States, 2008. MMWR Morb Mortal Wkly Rep 2011 Jun 03;60(21):694-699 [FREE Full text] [Medline: 21637183]

18. Huang E, Marlin RW, Medline A, Young SD, Daniels J, Klausner JD. Using grindr ${ }^{\mathrm{TM}}$, a smartphone social-networking application, to increase HIV self-testing among men who have sex with men in Los Angeles. Sex Transm Infect 2015;91(Suppl 2):A226. [doi: 10.1521/aeap.2016.28.4.341]

19. Elliot E, Rossi M, McCormack S, McOwan A. Identifying undiagnosed HIV in men who have sex with men (MSM) by offering HIV home sampling via online gay social media: a service evaluation. Sex Transm Infect 2016 Sep;92(6):470-473. [doi: 10.1136/sextrans-2015-052090] [Medline: 27221475]

20. Ko NY, Hsieh CH, Wang MC, Lee C, Chen CL, Chung AC, et al. Effects of internet popular opinion leaders (iPOL) among internet-using men who have sex with men. J Med Internet Res 2013 Feb 25;15(2):e40 [FREE Full text] [doi: 10.2196/jmir.2264] [Medline: 23439583]

21. Rhodes SD, McCoy TP, Tanner AE, Stowers J, Bachmann LH, Nguyen AL, et al. Using social media to increase HIV testing among gay and bisexual men, other men who have sex with men, and transgender persons: outcomes from a randomized community trial. Clin Infect Dis 2016 Jun 01;62(11):1450-1453 [FREE Full text] [doi: 10.1093/cid/ciw127] [Medline: 26980878]

22. Miller B. "They're the modern-day gay bar": exploring the uses and gratifications of social networks for men who have sex with men. Comput Human Behav 2015 Oct;51(Part A):476-482. [doi: 10.1016/j.chb.2015.05.023]

23. Sun CJ, Stowers J, Miller C, Bachmann LH, Rhodes SD. Acceptability and feasibility of using established geosocial and sexual networking mobile applications to promote HIV and STD testing among men who have sex with men. AIDS Behav 2015 Mar;19(3):543-552 [FREE Full text] [doi: 10.1007/s10461-014-0942-5] [Medline: 25381563]

24. Lelutiu-Weinberger C, Pachankis JE, Gamarel KE, Surace A, Golub SA, Parsons JT. Feasibility, acceptability, and preliminary efficacy of a live-chat social media intervention to reduce HIV risk among young men who have sex with men. AIDS Behav 2015 Jul;19(7):1214-1227 [FREE Full text] [doi: 10.1007/s10461-014-0911-z] [Medline: 25256808]

25. Chiu C, Lin D, Silverman A. McKinsey. 2012 May. China's social-media boom URL: http://www.mckinsey.com/ business-functions/marketing-and-sales/our-insights/chinas-social-media-boom [accessed 2017-06-29] [WebCite Cache ID 6rZZ61acM]

26. WEIXIN QQ. 2016. WeChat, a life style URL: http://weixin.qq.com/ [accessed 2017-01-03] [WebCite Cache ID 6nEHiqhNh]

27. UNAIDS. 2015. 2015 China AIDS response progress report URL: http://www.unaids.org/sites/default/files/country/ documents/CHN narrative report 2015.pdf [accessed 2017-01-03] [WebCite Cache ID 6nEHJOb7t]

28. CNNIC. 2016. Statistical report on internet development in China URL: https://cnnic.com.cn/IDR/ReportDownloads/ 201604/P020160419390562421055.pdf [accessed 2017-01-03] [WebCite Cache ID 6nEHrTpXX]

29. Eysenbach G. Improving the quality of Web surveys: the Checklist for Reporting Results of Internet E-Surveys (CHERRIES). J Med Internet Res 2004 Sep 29;6(3):e34 [FREE Full text] [doi: 10.2196/jmir.6.3.e34] [Medline: 15471760]

30. Blued. 2016. Blued Introduction URL: https://www.blued.com/en/ab.html [accessed 2017-01-03] [WebCite Cache ID $\underline{6 \text { nEHvFV7H] }}$

31. Han L, Bien CH, Wei C, Muessig KE, Yang M, Liu F, et al. HIV self-testing among online MSM in China: implications for expanding HIV testing among key populations. J Acquir Immune Defic Syndr 2014 Oct 01;67(2):216-221 [FREE Full text] [doi: 10.1097/QAI.0000000000000278] [Medline: 24991972]

32. Zhang L, Pentina I. Motivations and usage patterns of Weibo. Cyberpsychol Behav Soc Netw 2012 Jun;15(6):312-317. [doi: 10.1089/cyber.2011.0615] [Medline: 22703037]

33. Wallis C. New media practices in China: youth patterns, processes, and politics. Int J Comm 2011;5:406-436.

34. Tencent. 2016. Social Networks: QQ URL: https://www.tencent.com/en-us/system.html [accessed 2017-01-03] [WebCite Cache ID 6nEI3b58u]

35. Bien CH, Best JM, Muessig KE, Wei C, Han L, Tucker JD. Gay apps for seeking sex partners in China: implications for MSM sexual health. AIDS Behav 2015 Jun;19(6):941-946 [FREE Full text] [doi: 10.1007/s10461-014-0994-6] [Medline: 25572834]

36. Xie W. Social network site use, mobile personal talk and social capital among teenagers. Comput Human Behav 2014 Dec;41:228-235. [doi: 10.1016/j.chb.2014.09.042]

37. Dolan R, Conduit J, Fahy J, Goodman S. Social media engagement behaviour: a uses and gratifications perspective. Journal of Strategic Marketing 2015 Dec 23;24(3-4):261-277. [doi: 10.1080/0965254x.2015.1095222]

38. Rosenblatt G. Groundwire. 2010 Feb 01. The engagement pyramid: six levels of connecting people and social change URL: http://groundwire.org/blog/groundwire-engagement-pyramid/ [accessed 2017-01-03] [WebCite Cache ID 6nEI8brqC]

39. Tuvel Communications. SlideShare. 2011. The 5 levels of social media engagement URL: http://www.slideshare.net/ tuvelcomms/the-5-levels-of-social-media-engagement [accessed 2017-01-03] [WebCite Cache ID 6nEIB8qp8] 
40. Kane GC, Alavi M, Labianca G, Borgatti SP. What's different about social media networks? A framework and research agenda. MIS Quarterly 2014 Mar;38(1):275-304.

41. Davenport SW, Bergman SM, Bergman JZ, Fearrington ME. Twitter versus Facebook: exploring the role of narcissism in the motives and usage of different social media platforms. Comput Human Behav 2014 Mar;32:212-220. [doi: 10.1016/j.chb.2013.12.011]

42. Korda H, Itani Z. Harnessing social media for health promotion and behavior change. Health Promot Pract 2013 Jan;14(1):15-23. [doi: 10.1177/1524839911405850] [Medline: 21558472]

43. Cao B, Liu C, Stein G, Tang W, Best J, Zhang Y, et al. Faster and Riskier? Online context of sex seeking among men who have sex with men in China. Sex Transm Dis 2017 Apr;44(4):239-244. [doi: 10.1097/OLQ.0000000000000575] [Medline: 28282651]

44. Lariscy RW, Reber BH, Paek HJ. Examination of media channels and types as health information sources for adolescents: comparisons for black/white, male/female, urban/rural. J Broadcast Electron Media 2010 Mar 05;54(1):102-120. [doi: 10.1080/08838150903550444]

45. Hightow-Weidman LB, Muessig KE, Pike EC, LeGrand S, Baltierra N, Rucker AJ, et al. HealthMpowerment.org: building community through a mobile-optimized, online health promotion intervention. Health Educ Behav 2015 Aug;42(4):493-499 [FREE Full text] [doi: 10.1177/1090198114562043] [Medline: 25588932]

46. Anand T, Nitpolprasert C, Ananworanich J, Pakam C, Nonenoy S, Jantarapakde J, et al. Innovative strategies using communications technologies to engage gay men and other men who have sex with men into early HIV testing and treatment in Thailand. J Virus Erad 2015 Apr 01;1(2):111-115 [FREE Full text] [Medline: 27482400]

47. WHO. 2016. 2016 Call for innovative health technologies for low-resource settings URL: http://www.who.int/ medical devices/innovation/call 2014/en/ [accessed 2017-01-03] [WebCite Cache ID 6nEIErz1k]

48. Hawn C. Take two aspirin and tweet me in the morning: how Twitter, Facebook, and other social media are reshaping health care. Health Aff (Millwood) 2009;28(2):361-368 [FREE Full text] [doi: 10.1377/hlthaff.28.2.361] [Medline: 19275991]

49. Maher CA, Lewis LK, Ferrar K, Marshall S, De Bourdeaudhuij I, Vandelanotte C. Are health behavior change interventions that use online social networks effective? A systematic review. J Med Internet Res 2014 Feb 14;16(2):e40 [FREE Full text] [doi: 10.2196/jmir.2952] [Medline: 24550083]

50. Laranjo L, Arguel A, Neves AL, Gallagher AM, Kaplan R, Mortimer N, et al. The influence of social networking sites on health behavior change: a systematic review and meta-analysis. J Am Med Inform Assoc 2015 Jan;22(1):243-256 [FREE Full text] [doi: 10.1136/amiajnl-2014-002841] [Medline: 25005606]

51. Struik LL, Baskerville NB. The role of Facebook in Crush the Crave, a mobile- and social media-based smoking cessation intervention: qualitative framework analysis of posts. J Med Internet Res 2014 Jul 11;16(7):e170 [FREE Full text] [doi: 10.2196/jmir.3189] [Medline: 25016998]

52. Hefler M, Freeman B, Chapman S. Tobacco control advocacy in the age of social media: using Facebook, Twitter and change. Tob Control 2013 May;22(3):210-214. [doi: 10.1136/tobaccocontrol-2012-050721] [Medline: 23047890]

53. Cavallo DN, Tate DF, Ries AV, Brown JD, DeVellis RF, Ammerman AS. A social media-based physical activity intervention: a randomized controlled trial. Am J Prev Med 2012 Nov;43(5):527-532 [FREE Full text] [doi: 10.1016/j.amepre.2012.07.019] [Medline: 23079176]

54. Chen L, Shi J. Social support exchanges in a social media community for people living with HIV/AIDS in China. AIDS Care 2015;27(6):693-696. [doi: 10.1080/09540121.2014.991678] [Medline: 25532704]

55. Zou H, Wu Z, Yu J, Li M, Ablimit M, Li F, et al. Internet-facilitated, voluntary counseling and testing (VCT) clinic-based HIV testing among men who have sex with men in China. PLoS One 2013;8(2):e51919 [FREE Full text] [doi: 10.1371/journal.pone.0051919] [Medline: 23418417]

56. Tanner AE, Mann L, Song E, Alonzo J, Schafer K, Arellano E, et al. weCARE: a social media-based intervention designed to increase HIV care linkage, retention, and health outcomes for racially and ethnically diverse young MSM. AIDS Educ Prev 2016 Jun;28(3):216-230 [FREE Full text] [doi: 10.1521/aeap.2016.28.3.216] [Medline: 27244190]

57. Smith C. Expanded Dramblings. 2017. 100 amazing WeChat statistics and facts (July 2017) URL: http://expandedramblings. com/index.php/wechat-statistics/ [accessed 2017-01-03] [WebCite Cache ID 6nEIRNa0r]

58. Mozur P. NY Times. 2016. China, not Silicon Valley, is cutting edge in mobile tech URL: http://www.nytimes.com/2016/ 08/03/technology/china-mobile-tech-innovation-silicon-valley.html?_r=0 [accessed 2017-01-03] [WebCite Cache ID 6nEIcAi1M]

59. Cheng W, Cai Y, Tang W, Zhong F, Meng G, Gu J, et al. Providing HIV-related services in China for men who have sex with men. Bull World Health Organ 2016 Mar 01;94(3):222-227 [FREE Full text] [doi: 10.2471/BLT.15.156406] [Medline: 26966334]

60. Clinical Trials. 2016. Crowdsourcing: A public health campaign (Ongoing protocol) URL: https://clinicaltrials.gov/ct2/ show/NCT02796963 [accessed 2017-01-03] [WebCite Cache ID 6nEIp9Q8e]

61. DeWalt KM, DeWalt BR. Participant Observation: A Guide for Fieldworkers. Lanham, MD: Rowman Altamira; 2002.

62. Taggart T, Grewe ME, Conserve DF, Gliwa C, Roman Isler M. Social media and HIV: a systematic review of uses of social media in HIV communication. J Med Internet Res 2015 Nov 02;17(11):e248 [FREE Full text] [doi: 10.2196/jmir.4387] [Medline: 26525289] 
63. Jones C. Slacktivism and the social benefits of social video: sharing a video to 'help' a cause. First Monday 2015 May 04;20(5):- [FREE Full text]

64. News UBC. 2013 Nov 8. Slacktivism: 'Liking' on Facebook may mean less giving URL: http://news.ubc.ca/2013/11/08/ slacktivism-liking-on-facebook-may-mean-less-giving/ [accessed 2017-01-03] [WebCite Cache ID 6nEJ5aSnB]

65. Edwards B, Aris B, Shukor N. Cognitive load implications of social media in teaching and learning. J Multidiscip Eng Sci Technol 2015 Nov;2(11):3026-3030 [FREE Full text]

66. Fisher JD, Fisher WA, Bryan AD, Misovich SJ. Information-motivation-behavioral skills model-based HIV risk behavior change intervention for inner-city high school youth. Health Psychol 2002 Mar;21(2):177-186. [doi: 10.1037/0278-6133.21.2.177] [Medline: 11950108]

67. Neiger BL, Thackeray R, Van Wagenen SA, Hanson CL, West JH, Barnes MD, et al. Use of social media in health promotion: purposes, key performance indicators, and evaluation metrics. Health Promot Pract 2012 Mar;13(2):159-164. [doi: 10.1177/1524839911433467] [Medline: 22382491]

68. Shan LC, Panagiotopoulos P, Regan Á, De Brún A, Barnett J, Wall P, et al. Interactive communication with the public: qualitative exploration of the use of social media by food and health organizations. J Nutr Educ Behav 2015;47(1):104-108. [doi: 10.1016/j.jneb.2014.09.004] [Medline: 25449827]

69. Tang W, Han L, Best J, Zhang Y, Mollan K, Kim J, et al. Crowdsourcing HIV test promotion videos: a noninferiority randomized controlled trial in China. Clin Infect Dis 2016 Jun 01;62(11):1436-1442 [FREE Full text] [doi: 10.1093/cid/ciw171] [Medline: 27129465]

70. Zhang Y, Kim JA, Liu F, Tso LS, Tang W, Wei C, et al. Creative contributory contests to spur innovation in sexual health: 2 cases and a guide for implementation. Sex Transm Dis 2015 Nov;42(11):625-628 [FREE Full text] [doi: 10.1097/OLQ.0000000000000349] [Medline: 26462186]

71. Zhong L, Zeng G. Epidemiology of HIV/AIDS in rural area of China. Occup Heal 2014;30(23):3475-3478.

72. Westerman D, Spence PR, Van Der Heide B. Social media as information source: recency of updates and credibility of information. J Comput-Mediat Comm 2013 Nov 08;19(2):171-183. [doi: 10.1111/jcc4.12041]

\title{
Abbreviations
}

AGFI: adjusted goodness of fit index

aOR: adjusted odds ratio

CFI: comparative fit index

CFA: confirmatory factor analysis

CMIN/DF: chi-squared test of minimum discrepancy divided by degrees of freedom

GFI: goodness of fit index

MSM: men who have sex with men

NFI: normed fit index

RMSEA: root mean square error of approximation

\author{
Edited by G Eysenbach; submitted 03.01.17; peer-reviewed by J Jiang, H Zhao; comments to author 30.03.17; revised version received \\ 25.04.17; accepted 02.06.17; published 19.07.17 \\ Please cite as: \\ Cao B, Liu C, Durvasula M, Tang W, Pan S, Saffer AJ, Wei C, Tucker JD \\ Social Media Engagement and HIV Testing Among Men Who Have Sex With Men in China: A Nationwide Cross-Sectional Survey \\ J Med Internet Res 2017;19(7):e251 \\ URL: http://www.jmir.org/2017/7/e251/ \\ doi: 10.2196/jmir.7251 \\ PMID: 28724510
}

CBolin Cao, Chuncheng Liu, Maya Durvasula, Weiming Tang, Stephen Pan, Adam J Saffer, Chongyi Wei, Joseph D Tucker. Originally published in the Journal of Medical Internet Research (http://www.jmir.org), 19.07.2017. This is an open-access article distributed under the terms of the Creative Commons Attribution License (https://creativecommons.org/licenses/by/4.0/), which permits unrestricted use, distribution, and reproduction in any medium, provided the original work, first published in the Journal of Medical Internet Research, is properly cited. The complete bibliographic information, a link to the original publication on http://www.jmir.org/, as well as this copyright and license information must be included. 